NASA/TM-2002-211487

\title{
Modeling International Space Station (ISS) Floating Potentials
}

Dale C. Ferguson

Glenn Research Center, Cleveland, Ohio

Barbara Gardner

Science Applications International Corporation, San Diego, California 
Since its founding, NASA has been dedicated to the advancement of aeronautics and space science. The NASA Scientific and Technical Information (STI) Program Office plays a key part in helping NASA maintain this important role.

The NASA STI Program Office is operated by Langley Research Center, the Lead Center for NASA's scientific and technical information. The NASA STI Program Office provides access to the NASA STI Database, the largest collection of aeronautical and space science STI in the world. The Program Office is also NASA's institutional mechanism for disseminating the results of its research and development activities. These results are published by NASA in the NASA STI Report Series, which includes the following report types:

- $\quad$ TECHNICAL PUBLICATION. Reports of completed research or a major significant phase of research that present the results of NASA programs and include extensive data or theoretical analysis. Includes compilations of significant scientific and technical data and information deemed to be of continuing reference value. NASA's counterpart of peerreviewed formal professional papers but has less stringent limitations on manuscript length and extent of graphic presentations.

- TECHNICAL MEMORANDUM. Scientific and technical findings that are preliminary or of specialized interest, e.g., quick release reports, working papers, and bibliographies that contain minimal annotation. Does not contain extensive analysis.

- CONTRACTOR REPORT. Scientific and technical findings by NASA-sponsored contractors and grantees.
- CONFERENCE PUBLICATION. Collected papers from scientific and technical conferences, symposia, seminars, or other meetings sponsored or cosponsored by NASA.

- SPECIAL PUBLICATION. Scientific, technical, or historical information from NASA programs, projects, and missions, often concerned with subjects having substantial public interest.

- TECHNICAL TRANSLATION. Englishlanguage translations of foreign scientific and technical material pertinent to NASA's mission.

Specialized services that complement the STI Program Office's diverse offerings include creating custom thesauri, building customized data bases, organizing and publishing research results ... even providing videos.

For more information about the NASA STI Program Office, see the following:

- Access the NASA STI Program Home Page at http://www.sti.nasa.gov

- E-mail your question via the Internet to help@sti.nasa.gov

- Fax your question to the NASA Access Help Desk at 301-621-0134

- Telephone the NASA Access Help Desk at 301-621-0390

- Write to:

NASA Access Help Desk

NASA Center for AeroSpace Information 7121 Standard Drive

Hanover, MD 21076 
NASA/TM-2002-211487

AIAA-2002-0933

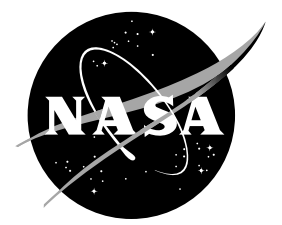

\section{Modeling International Space Station (ISS) Floating Potentials}

Dale C. Ferguson

Glenn Research Center, Cleveland, Ohio

Barbara Gardner

Science Applications International Corporation, San Diego, California

Prepared for the

40th Aerospace Sciences Meeting and Exhibit

sponsored by the American Institute of Aeronautics and Astronautics

Reno, Nevada, January 14-17, 2002

National Aeronautics and

Space Administration

Glenn Research Center

May 2002 
Available from

NASA Center for Aerospace Information 7121 Standard Drive

Hanover, MD 21076
National Technical Information Service 5285 Port Royal Road Springfield, VA 22100

Available electronically at http:/ /gltrs.grc.nasa.gov/GLTRS 


\title{
MODELING INTERNATIONAL SPACE STATION (ISS) FLOATING POTENTIALS
}

\author{
Dale C. Ferguson, \\ National Aeronautics and Space Administration \\ Glenn Research Center \\ Cleveland, Ohio 44135 \\ Barbara Gardner \\ Science Applications International Corporation \\ San Diego, California 92121
}

\begin{abstract}
$\underline{\text { ABSTRACT }}$
The floating potential of the International Space Station (ISS) as a function of the electron current collection of its high voltage solar array panels is derived analytically. Based on Floating Potential Probe (FPP) measurements of the ISS potential and ambient plasma characteristics, it is shown that the ISS floating potential is a strong function of the electron temperature of the surrounding plasma. While the ISS floating potential has so far not attained the pre-flight predicted highly negative values, it is shown that for future mission builds, ISS must continue to provide two-fault tolerant archazard protection for astronauts on EVA.
\end{abstract}

\section{INTRODUCTION}

The International Space Station (ISS), with its huge dimensions and high voltage solar arrays, is easily the biggest space plasma experiment ever carried out. In 1990 and 1991, a "Tiger Team" of experts convened to determine what plasma interactions ISS might have, and concluded that its $160 \mathrm{~V}$ solar arrays, grounded at their negative terminals, would cause the ISS structure to "float" at a potential some $140 \mathrm{~V}$ negative of the surrounding plasma, a voltage higher than the breakdown strength of its anodized aluminum structure. ISS would arc itself to death by slowly destroying its thermal coatings through arcs into the ambient LEO plasma ${ }^{1}$. A computer tool, the Environments WorkBench (EWB) was created to allow calculation of floating potentials on ISS $^{2}$. It gave further credence to the $140 \mathrm{~V}$ charging estimates. Further work by another Tiger Team in the year 2000 determined that certain parts of the astronauts' EMUs (spacesuits) could arc in simulated LEO plasmas at voltages as low as $60 \mathrm{~V}$ negative ${ }^{3,4}$, and the arcs would carry enough current to cause cardiac arrest. For an account of how the ISS program responded to plasma issues, see Ferguson ${ }^{5}$.

In response to anticipated plasma problems, Plasma Contacting Units (PCUs) were included in the ISS design. They would work to generate a high density xenon plasma which would make contact with the ambient LEO plasma, and effectively ground the ISS structure to its surroundings. In December 2000 , the first set of ISS high voltage arrays were installed and turned on, with the plasma contactors operating to control ISS potentials. ISS has two redundant PCUs, each of which can fully control its potential. To fully control against the catastrophic astronaut arc hazard, a third control was necessary. Passive techniques, such as shunting the arrays or turning them into their own wakes, would need to be demonstrated on orbit by measuring the resulting ISS potentials. 
A device to measure ISS potentials and characteristics of the surrounding plasma, the Floating Potential Probe, was hurriedly developed and launched coincident with the first set of high voltage solar arrays ${ }^{6}$.

FPP was used successfully to demonstrate that the passive techniques, when applied to both arrays, would completely eliminate the hazard. Furthermore, a series of experiments with the FPP showed that under most plasma conditions, even with no controls in place, the ISS potential for the early mission builds would not exceed the anodized aluminum breakdown strength. With no PCUs operating, during about eleven days of data taking, the highest documented FPP potential was about 26 volts negative of the surrounding plasma. This corresponds to a maximum potential anywhere on ISS of about 35 volts negative (see below), far below the predictions made by the Tiger Teams. Unfortunately, contact with the FPP was lost shortly thereafter, and all efforts since then have failed to recover it. As shown in Ferguson ${ }^{5}$, the reasons for the faulty predictions of ISS potentials were as varied as they were unexpected. In this paper, we summarize how ISS potentials are related to the currents collected by the solar arrays, and make confident predictions for future ISS potentials.

\section{$\underline{\text { FUNDAMENTALS }}$}

It is axiomatic that in a high-density plasma such as the equatorial LEO plasma, ion and electron currents to isolated surfaces or to an entire spacecraft will be equal. If an electron-emitting device is included, electron emission must be added to ion collection. The spacecraft will "float" at such a potential that the current balance is maintained. See figure 1 .

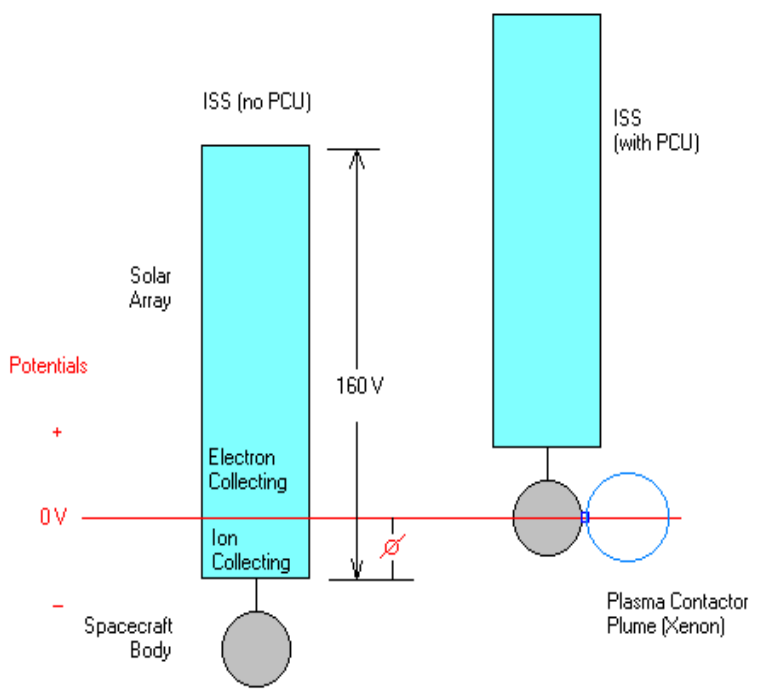

Figure 1. ISS in the LEO plasma. Ion collection must balance electron collection unless there is a plasma contactor. Predictions were that $\varphi$ would be about $140 \mathrm{~V}$. FPP measurements showed it to be $<40 \mathrm{~V}$.

For surfaces bigger than a Debye length, ion collection will be essentially due to the unidirectional ram ion flux against the ram surface area, which depends only on the velocity and ion density. Electron collection will be onto all non-wake surfaces and is essentially thermal and omnidirectional. Electron collection depends both on the electron density and electron temperature. The ISS floating potential in the absence of PCU operation is a balance of electron collection by the solar arrays and ion collection by bare metal on the ISS structure.

Estimates of ISS solar array electron collection prior to ISS launch were based on ground and flight tests that were essentially in disagreement ${ }^{7-9}$. Early ground tests had shown that electron collection on the ISS solar arrays decreased with increasing electron temperature, rather than increasing, as with most electron collectors. Modeling ${ }^{10}$ showed that this was due to the detailed geometry for electron collection at the edges of solar cells, 
which are partially covered by the solar cell coverslides. Space flight tests ${ }^{8,9}$ disagreed with each other by a factor of about 30 . The PASP Plus electron collection was much greater than that seen on SAMPIE. SAMPIE tested modified ISS solar cells also, and they seemed to show that the PASP Plus results (with a flexible substrate, as on ISS) might better represent ISS collection, where the flexible polyimide array substrate would allow more collection at cell edges ${ }^{8}$. However, it is also possible that bowing of the flexible substrate can choke off collection at the cell edges. In any event, predictions for ISS were based mainly on the PASP Plus results, with electron temperature dependence derived from models of the ground experiments. As it turned out, even the low SAMPIE results for electron collection were an overestimate of the collection on ISS. As a result, $\varphi$, the amount of ISS charging, was severely overestimated.

But that wasn't all. In addition, significant areas of bare metal on ISS were overlooked. The wires on the solar array masts (amounting to several square meters) were grounded to structure. They had been neglected because originally they had not been grounded, and would not have influenced the floating potential. These wires had another effect. They were ideally placed to maximize potential excursions due to the so-called vxB effect. Motion of ISS through the Earth's magnetic field sets up an electric field in the plasma rest frame that makes different parts of the structure take up different potentials with respect to the plasma. This effect was clearly seen in the FPP data, and confused interpretation of the early FPP results ${ }^{11}$. Even accounting for the vxB effect and the reduced electron current collection of the solar arrays, EWB models of ISS potentials still could only be made to agree with FPP results if an additional 10 square meters of ram-ion collector existed somewhere near the ISS center-line $^{12}$. While it is still unknown what exposed metal surfaces were responsible, a clue was obtained when the Space Shuttle docked to ISS during mission 6A. The Space Shuttle's bell nozzles should have provided another 10 square meters or so of ion collecting area, causing the ISS charging to go down. Instead, it went up, indicating that the Shuttle was placing the ISS exposed conductors into its wake. This indicates that the ISS collecting area may be on the docking adapter or the other ISS modules in the Shuttle wake. Later, when the Shuttle left, the PCU currents went down, indicating that perhaps the newly installed airlock module added even more ion collecting area to ISS.

The moral of the story is an old and familiar one to computer modelers - GIGO (garbage in, garbage out). Although the EWB models of ISS floating potentials were, it is believed, physically correct, they gave the wrong predictions because of errant input parameters. Below, we discuss the physics of ISS current collection and its bearing on ISS floating potential. This will allow us to make analytical predictions for future ISS missions that (we believe) are quantitative and correct.

\section{ISS SOLAR ARRAY CURRENT COLLECTION AND FPP DATA}

All measurements of ISS solar array electron collection have shown that it increases dramatically at voltages greater than about 100 volts. Assuming that the electron temperature and density dependences are separable from the voltage dependence, and that writing the amount of charging as $\varphi$, we can write the electron collection as

$I_{e}=I\left(n_{e}, T_{e}\right) \int_{0}^{160-\varphi} I(V) d V$.

See figure 1. This assumes, correctly, that the solar array string voltage increases linearly with cell number and area. It also assumes 
that the electron collection of negatively biased cells is zero. We can, and will, ignore the ion collection of the solar array compared to the ion collection of other ISS areas.

Assuming I(V) $\alpha \mathrm{V}^{\mathrm{x}}$, we can write

$I_{e}=\left(I\left(n_{e}, T_{e}\right)[160-\varphi]^{1+x}\right) /(1+x)$.

ISS ion collection can be written approximately as

$\mathrm{I}_{\mathrm{i}}=\mathrm{n}_{\mathrm{i}} \mathrm{v} \mathrm{A}_{\mathrm{i}}$.

Here, $n_{i}$ and $n_{e}$ are the ion and electron number densities, $v$ is the ISS velocity (approximately constant), $T_{e}$ is the electron temperature, and $A_{i}$ is the ram-facing area. Current balance demands that $I_{i}=I_{e}$. Here, our problem is what is the dependence of I on V for the solar arrays. From two different experiments on $\mathrm{SAMPIE}^{8}$, we can estimate that from about +100 to about $+160 \mathrm{~V}$, ISS array electron collection is approximately power-law, with an exponent ${ }^{14}$ of about 3 . If this is true, then

$$
[160-\varphi]=\left[\left(4 \mathrm{I}_{\mathrm{i}}\right) / \mathrm{I}\left(\mathrm{n}_{\mathrm{e}}, \mathrm{T}_{\mathrm{e}}\right)\right]^{1 / 4} \text {. }
$$

By the way, if the electron collection current is less than the ion current, no charging will occur. That is, $(160-\varphi)<160$.

Now, all that remains is to determine $I\left(n_{e}, T_{e}\right)$. Unfortunately, it can't be found easily from PCU currents. This is because vxB makes changes in the solar array potentials, and the strong dependence of current on voltage may mask the dependence on the other quantities. Also, the still unknown amount of ion collecting area will subtract an unknown amount of solar array collection from the PCU currents. So, we will attempt to back out the plasma dependences from FPP measurements of the floating potential.

First, we must subtract out the vxB contribution. Fortunately our models of vxB (see Gardner, et $\mathrm{al}^{11}$, at this conference) are so good that the vxB can be subtracted out with a high degree of accuracy. Figure 2 below shows models of $\mathrm{vxB}$ computed by EWB for one day in April 2001, compared with FPP measurements for the same day. Of special interest is the close correspondence of the EWB model of $\mathrm{vxB}$ with the FPP measurements when there was no charging by the solar arrays (when the solar array electron collection was less than the ram ion collection). This holds for more than $3 / 4$ of each orbit. Here, vbody is $-\varphi$ as we have defined it in this paper, as modified by vxB. Other features of interest are the success of the EWB models in predicting times of charging (essentially every dawn) and the late morning times when the arrays started to be shunted and therefore didn't produce the predicted amounts of charging. By turning the arrays off in the EWB predictions, we found very good vxB values, which were subsequently subtracted from the FPP measured vbody values to find $\varphi$. In what follows, we will use this quantity to try to determine the dependences on electron density and temperature. 


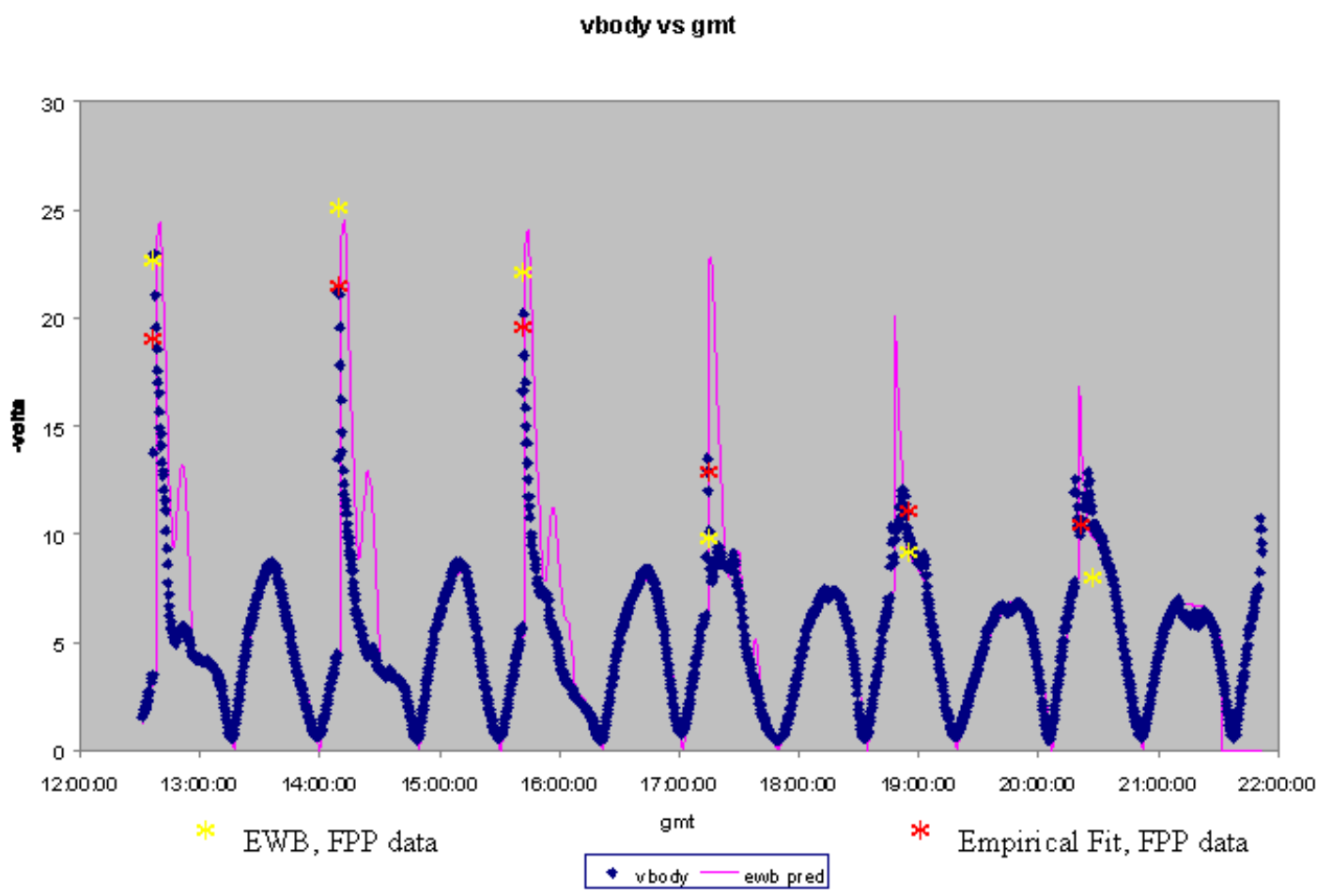

Figure 2. FPP data and EWB model fits for April 11, 2001. Data are blue points; EWB model is the magenta curve.

In 2001, a dependence of $\varphi$ on plasma parameters was found in what is now called the Ferguson-Morton relation (see Ferguson ${ }^{5}$ ). Here we use the same data to obtain relations for $(160-\varphi)$ for inclusion in formula (3). The FPP data used were for times when the arrays were ram-pointing or sun-pointing in the morning side of the orbit. No PCU was operating. Because of a peculiarity of the FPP, no plasma parameters could be determined when the total charging was greater than about 10 volts. Therefore, for the charging peaks used here, the FPP-measured ambient plasma parameters for times just preceding the charging events were used. Unknown changes in the few minutes before the charging peak was reached have undoubtedly contributed to the noise evident in the model fits. For a discussion of the validity of the FPP measurements of ambient plasma parameters, see the paper by Morton and Minow ${ }^{13}$.
Figure 3 shows $(160-\varphi)$ versus $n_{e}$ for the dates April 11 through April 13, 2001. A significant dependence is evident, and is found to be about $n_{e}^{-0.0182}$. Figure 4 shows $(160-\varphi)$ versus $T_{e}$ for 4/11-4/13/2001. Again, a significant dependence is evident, and is found to be about $T_{e}{ }^{0.1126}$. Finally, figure 5 shows the FPP measured data compared with a best-fit combined dependence, which is more significant than on either factor alone, and is about $\mathrm{n}_{\mathrm{e}}{ }^{-0.01} \mathrm{~T}_{\mathrm{e}}{ }^{0.07}$. For the combined parameters, the correlation coefficient is about 0.86 . We will call this the best fit:

$(160-\varphi)=217.24 \mathrm{n}_{\mathrm{e}}^{-0.01} \mathrm{~T}_{\mathrm{e}}^{0.07}$.

We will substitute this into formula (3) to determine the dependence of the solar array electron current on electron density and temperature. 
(160-obschg)

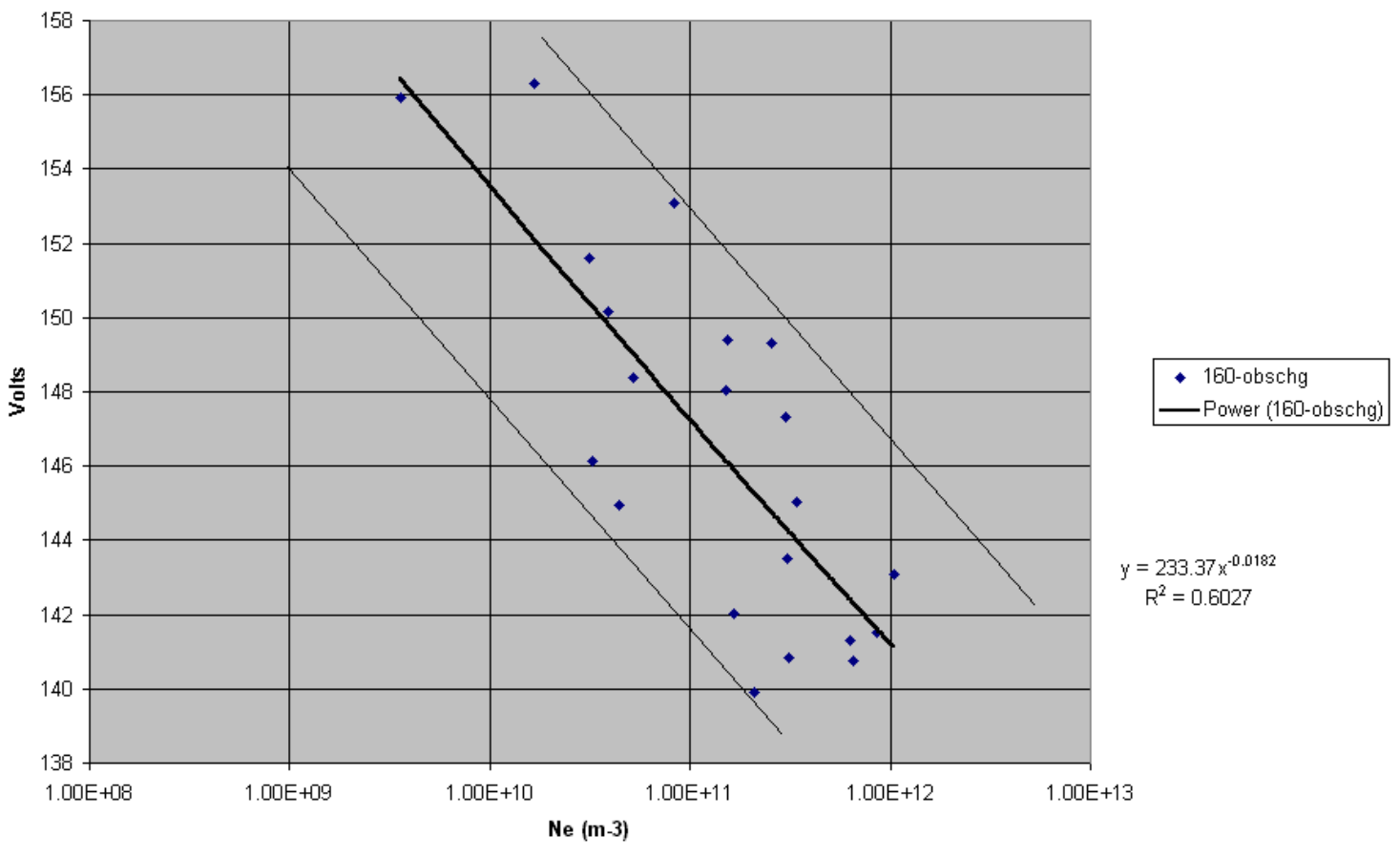

Figure 3. Dependence of charging on $\mathrm{n}_{\mathrm{e}}$. Outlying lines encompass all points.

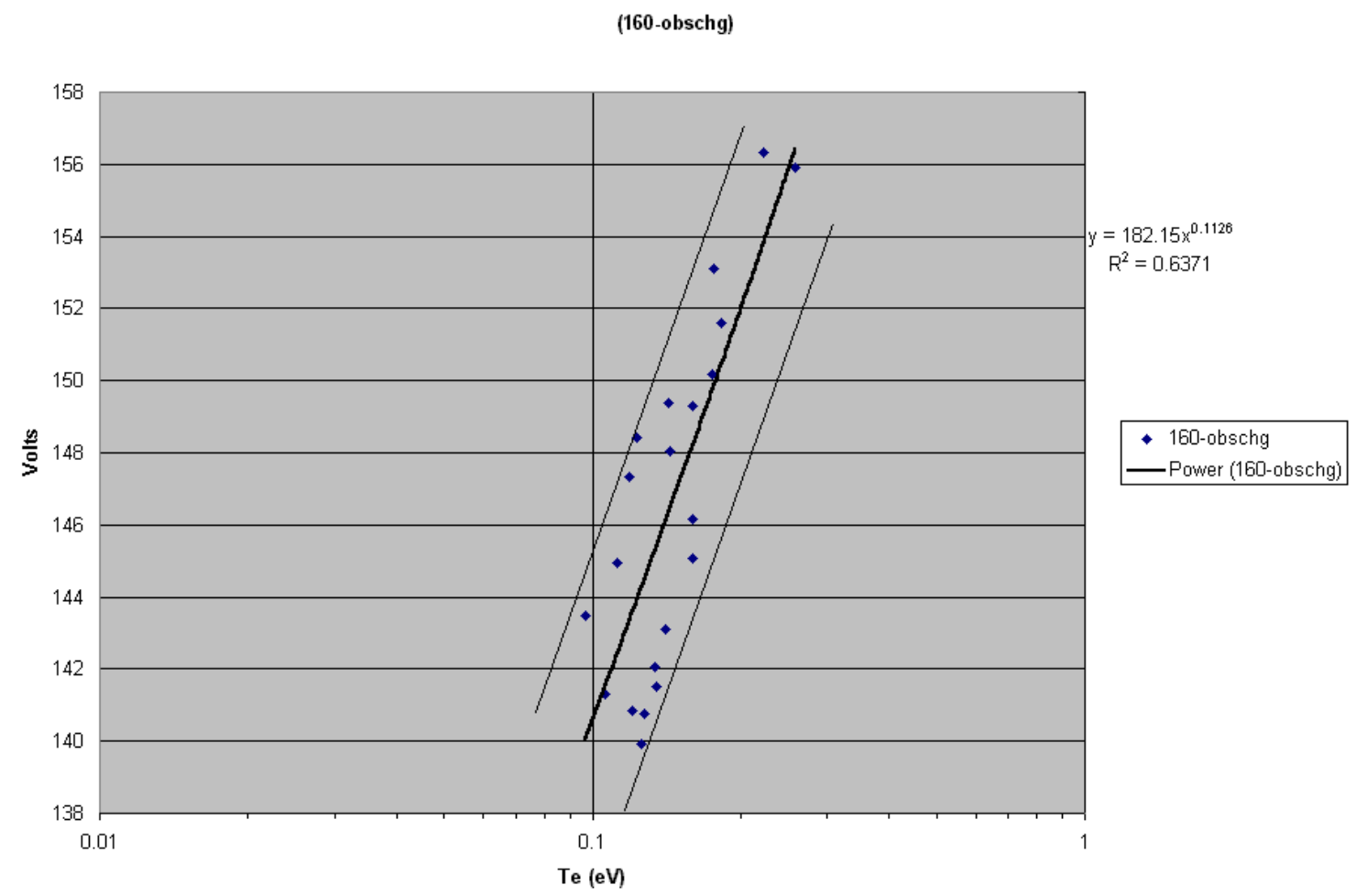

Figure 4. Dependence of charging on Te. Outlying lines encompass all points. 


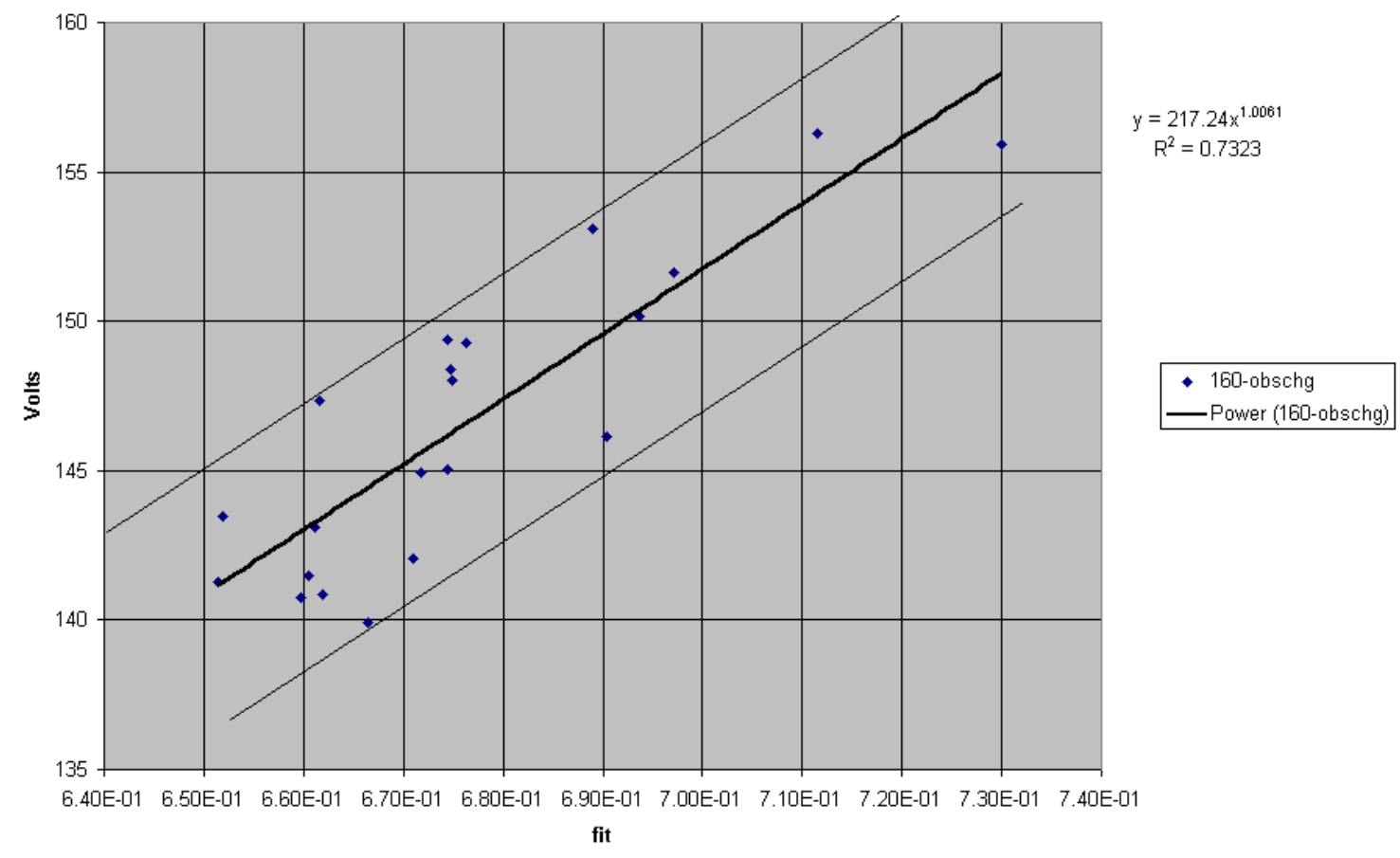

Figure 5. Observed charging versus the fitted function given in the text. Again, outlying lines encompass all points.

\section{CONCLUSIONS}

From our best fit and formula (3), and knowing that the electron and ion densities are equal, we can see that

$\mathrm{I}_{\mathrm{e}} \alpha \mathrm{V}^{3} \mathrm{n}_{\mathrm{e}}{ }^{1.04} \mathrm{~T}_{\mathrm{e}}{ }^{-0.28}$.

This is not surprising. First, the electron density dependence is nearly linear, as is typical for many types of electron collection. Also, the negative dependence of the current on the electron temperature is reproduced. More importantly, equation (3) now allows us to determine how changes in either electron temperature or the area of the solar arrays will affect the amount of charging.

Before doing that however, let us try to determine how safe ISS is to arcing with no changes to its April 11-13 configuration.
Since the maximum vxB was about 9 volts, and the outlying data points in our best fit were about 4 volts from the best fit line, we need to allow ourselves 13 volts margin on our predictions (there is no significant correlation between $\mathrm{vxB}$ and our deviations). At present, ISS safety rules prevent the structure from being more than 40 volts negative. Taking a typical (FPP results show) morning electron density of $10^{11}$ and temperature of 0.1 electron volts, we find $(160-\varphi)=144$ volts. Subtracting our fitting margin, we have 131 volts. This is 11 volts away from our $120 \mathrm{~V}$ safety rule. However, the electron temperature at dawn can be as low as 0.06 electron volts and the electron density can be as high as $10^{12}$. With these parameters, we find $(160-\varphi)=135 \mathrm{~V}$, and subtracting 13 , we have $122 \mathrm{~V}$. This is only 2 volts away from violating our safety rule. Thus, some hazard control must be used to 
avoid breaking the safety rules, even without changes in ISS configuration.

One might argue that since the arcing problem has only been shown to exist for components at $-60 \mathrm{~V}$ or farther from the plasma, we are artificially restricting ourselves by using $-40 \mathrm{~V}$ instead of $-60 \mathrm{~V}$ as our safety criterion. However, even $-60 \mathrm{~V}$ may be a problem in future mission builds, as we will show now.

In mission builds $12 \mathrm{~A}$ and beyond, an S0 truss will be employed, which extends horizontally and with solar arrays at the ends, will accentuate the $\mathrm{vxB}$ voltage variation. EWB simulations show that various parts of the structure will have vxB differences of as much as 25 volts. Also, $12 \mathrm{~A}$ and later mission builds will use at least two sets of solar arrays similar to the one set in use up to then. This will increase the solar array electron collection by a factor of two. In equation (3), doubling the solar array collection will increase the charging, such that

$$
(160-\varphi 2)=(160-\varphi 1)(1 / 2)^{1 / 4} \text {. }
$$

The minimum $(160-\varphi 1)$ FPP measured was about $140 \mathrm{~V}$. Applying (5) above, we find $(160-\varphi)=0.84(140)=118 \mathrm{~V}$. Even without added vxB, this will violate the $-40 \mathrm{~V}$ criterion.

If we allow ourselves to maximize vxB, we must subtract another $25 \mathrm{~V}$. Now we have violated the $-60 \mathrm{~V}$ limit by 7 volts. Even ISS structural materials might arc at these voltages.

But what about the added ion-collection area on future mission builds? First of all, we are not even sure what it was on earlier builds. One possibility is that it consisted of bare metal quarter-turn fasteners used to attach the micrometeoroid shields. If that is the case, extra ion collection will have to wait for added manned modules with ram-facing sides. As far as we know, there are no plans to add 10 square meters of ion collection area. If it were there, the added vxB would still put the potential at some points on ISS close to the $-60 \mathrm{~V}$ limit.

Finally, with the solar cycle winding down, the conditions for severe charging (low electron temperatures) will become more prevalent. It is imperative for safety reasons that a two-fault tolerant approach continue to be used whenever astronauts are on EVA. With the increasing power demands on ISS, the current passive techniques may no longer be an option, because of the severely reduced power they imply. Other alternatives to PCUs may be required ${ }^{15}$.

\section{REFERENCES}

1. D.C. Ferguson, D.B. Snyder and R. Carruth, 1990, Report of the Joint Workshop of the Space Station Freedom Plasma Interactions and Effects Working Group, the Space Station Freedom Plasma Working Group, and the Space Station Freedom EMI/EMC and Electromagnetic Effects Working Group on Evaluation of Impacts of Space Station Freedom Grounding Configurations, May 2224, 1990. Final Report, Aug. 21, 1990. Available through NASA Glenn Research Center.

2. R. Chock and D.C. Ferguson, 1997, "Environments Workbench-An Official NASA Space Environments Tool," Proceedings of the 32nd Intersociety Energy Conversion Engineering Conference, Honolulu, Hawaii, Paper IECEC-97452, p. 752 .

3. M.R. Carruth et al., 2001, "ISS and Space Environment Interactions Without Operating Plasma Contactor,” AIAA Paper 2001-0401. 
4. T. Schneider et aL., 2002, "Minimum Arc Threshold Voltage Experiments on Extravehicular Mobility Unit Samples," AIAA Paper 2002-1040.

5. D.C. Ferguson, 2001, "Charging Of The International Space Station Due To Its High Voltage Solar Arrays," Proceedings of the XVIIth Space Photovoltaic Research and Technology Conference, in press.

6. T. Adams et al., 2002, "The Floating Potential Probe-An Autonomous Plasma Instrument Deployed on the ISS," AIAA Paper 2002-1038.

7. M.C. Felder et al., 1993, "Results of Tests Conducted in Tank 5 for Interactions Between Space Station Freedom and Plasma," PIR\#268, NASA LeRC (now GRC), January 22, 1993.

8. D.C. Ferguson, 1997, "Comparison of Electron Current Collection by Space Station Solar Arrays as Measured by SAMPIE and PASP Plus," in the Photovoltaic Array Space Power Plus Diagnostics (PASP Plus) Experiment Final Report, D.A. Guidice, V.A. Davis, H.B. Curtis, D.E. Hastings, F.L.Knight, D.C. Marvin, K.P. Ray, P.S. Severance, J.D. Soldi, M. Van Riet, co-authors, PL-TR97-1013, March, 1997.

9. V.A. Davis, 1997, "Parasitic Current Collection by PASP Plus," in the Photovoltaic Array Space Power Plus Diagnostics (PASP Plus) Experiment Final Report, D.A. Guidice, D.C. Ferguson, H.B. Curtis, D.E. Hastings, F.L.Knight, D.C. Marvin, K.P. Ray, P.S. Severance, J.D. Soldi, M. Van Riet, co-authors, PL-TR-97-1013, March, 1997.
10. R.C. Chock, 1991, "NASCAP/LEO Simulations, SSF Solar Cell Geometries," Minutes of the Electrical Grounding Tiger Team Meeting, May 14-17, 1991, Boeing Trade Zone, Huntsville, Alabama.

11. B. Gardner, I. Katz, and V. Davis, 2002, "ISS Plasma Contactor Emission Currents: Flight Data and Model Comparison," AIAA Paper 2002-1041.

12. D.C. Ferguson, G.B. Hillard and T.L. Morton, 2001, "The Floating Potential Probe (FPP) for ISS-Operations and Initial Results," $7^{\text {th }}$ Spacecraft Charging Technology Conference, Noordwijk, Netherlands, April 23-27.

13. T. Morton and J. Minow, 2002, "Floating Potential Probe Langmuir Probe Data Reduction Results," AIAA Paper 2002-0936.

14. PASP plus measurements (see ref. 9) give a higher value for the power law exponent with voltage, but it is believed that the Space Shuttle was a more stable platform in floating potential, and the SAMPIE results are from a larger sample than PASP Plus, with fewer outside cell edges, and thus more similar to the real ISS array. Even taking an exponent of four only changes our final results by about 4 volts from the exponent $=3$ case.

15. D.C. Ferguson, 2002, "Alternatives to the ISS Plasma Contacting Units," AIAA Paper 2002-0934. 
